CLINICAL STUDY

\title{
Erythropoietin and vascular endothelial growth factor as risk markers for severe hypoglycaemia in type 1 diabetes
}

\author{
P L Kristensen $^{1}$, U Pedersen-Bjergaard ${ }^{1}$, C Schalkwijk ${ }^{2}$, N V Olsen ${ }^{3}$ and B Thorsteinsson ${ }^{1,4}$ \\ ${ }^{1}$ Endocrinology Section, Department of Cardiology and Endocrinology, Hillerød Hospital, Dyrehavevej 29, DK-3400 Hillerod, Denmark, ${ }^{2}$ Department \\ of Internal Medicine, University of Maastricht, NL-6202 Maastricht, The Netherlands, ${ }^{3}$ Department of Neuroanaesthesia, The Neuroscience Centre, \\ Copenhagen University Hospital (Rigshospitalet), DK-2100 Copenhagen, Denmark and ${ }^{4}$ Faculty of Health Sciences, University of Copenhagen, DK-2200 \\ Copenhagen, Denmark
}

(Correspondence should be addressed to P L Kristensen; Email: pelk@hih.regionh.dk)

\begin{abstract}
Objective: Circulating erythropoietin (EPO) and vascular endothelial growth factor (VEGF) increase during hypoglycaemia and may represent protective hormonal counter-regulatory responses. We tested the hypothesis that low levels of EPO and VEGF are associated with a higher frequency of severe hypoglycaemia in a cohort of patients with type 1 diabetes.

Design: Prospective observational follow-up study.

Methods: Totally 219 patients with type 1 diabetes (41\% females, age $46 \pm 13$ years (mean \pm s.D.), duration of diabetes $21 \pm 12$ years, and HbAlc $8.5 \pm 1.1 \%$ ) were followed in a 1-year observational study. Plasma EPO and serum VEGF levels were measured at baseline with ELISA. Events of severe hypoglycaemia defined by third party assistance were recorded and validated in telephone interviews within $24 \mathrm{~h}$.

Results: Totally 235 episodes of severe hypoglycaemia (1.1 episodes per patient-year) were reported by 82 patients (37\%). At baseline, plasma EPO was 8.6 (3.1-34.3) U/l (median (range)), and serum VEGF was $52.2(6.6-337) \mathrm{pg} / \mathrm{ml}$. The levels of EPO and VEGF were not associated with frequency of severe and mild hypoglycaemia. The levels of EPO were not associated with age, sex, duration of diabetes, body mass index, HbAlc, C-peptide level or hypoglycaemia awareness status. The levels of VEGF were positively associated with age and female sex.

Conclusions: Although several studies suggest that VEGF and EPO may affect brain function during hypoglycaemia, this study does not support random VEGF or EPO levels to determine future risk of severe hypoglycaemia in people with type 1 diabetes.
\end{abstract}

European Journal of Endocrinology 163 391-398

\section{Introduction}

In type 1 diabetes, the unavoidable and frequent episodes of mild hypoglycaemia may develop into severe hypoglycaemia with profound cognitive dysfunction. The primary protective mechanisms include hormonal counter-regulation to mobilise endogenous glucose. The classic hormonal counter-regulation consists of a rise in glucagon, adrenaline and noradrenaline to be followed by cortisol and GH. New data show that other circulating proteins are also stimulated by mild hypoglycaemia. Two such substances are erythropoietin (EPO) (1) and vascular endothelial growth factor (VEGF) (2-5), both of which are induced via the transcription factor hypoxia-inducible factor (HIF).

HIFs are proteins that mediate a protective response to hypoxia. Certain HIF subunits are also activated during hypoglycaemia (6). When activated, HIF promotes the formation of EPO and VEGF, but also the glucose transporter-1 (GLUT1; reviewed in (7)). This latter mechanism may increase cellular uptake of glucose and thereby provide protection against hypoglycaemia.

In vitro studies suggest that EPO may preserve cellular function during hypoglycaemia (8-10). Low EPO levels may be associated with more pronounced cerebral dysfunction during hypoglycaemia than higher levels in people with type 1 diabetes (1). Hypoglycaemia induces stabilisation of VEGF mRNA (11), and GLUT1 (or SLC2A1 as listed in the HUGO Database) mRNA is up-regulated by VEGF (12). A high VEGF rise during hypoglycaemia is reportedly associated with preservation of cognitive function during hypoglycaemia in healthy adults (4). Thus, high levels of circulating EPO or VEGF may preserve cognitive function during hypoglycaemia and thereby help the patient to prevent episodes of severe hypoglycaemia. Therefore, we tested the hypothesis that low levels of circulating EPO and VEGF are associated with a higher frequency of severe hypoglycaemia in a cohort of patients with type 1 diabetes. 


\section{Subjects and methods}

\section{Subjects and design}

The present study is a post hoc study of blood samples gathered during a prospective study designed to evaluate risk markers for severe hypoglycaemia in type 1 diabetes (13). Briefly, adults with type 1 diabetes for more than 2 years and not treated with angiotensinconverting enzyme inhibitors (ACEIs) or angiotensin II receptor blockers (ARBs) were recruited from our outpatient clinic. The reason for excluding subjects treated with ACEIs and ARBs is that such agents may lead to changes in concentrations of EPO and VEGF, since angiotensin II affects HIF - the common transcription factor of EPO and VEGF (14). A total of 269 eligible subjects gave informed consent to participate. Thirty-nine subjects dropped out during the study period (38 withdrew their consent and 1 died). Furthermore, 11 subjects were excluded as they commenced treatment with ACEIs or ARBs. Subjects medicated with $\beta$-receptor antagonists $(n=5)$ or psychopharmacological agents $(n=3)$ were not excluded. A total of 219 subjects completed the study. Clinical characteristics of the participating subjects appear from Table 1 . The study was approved by the regional ethics committee. Results regarding the association between renin-angiotensin system components and risk of severe hypoglycaemia have been published elsewhere $(13,15)$.

\section{Baseline data}

At baseline, the participants completed a questionnaire assessing previous experience of hypoglycaemia and self-estimated state of hypoglycaemic awareness. State of awareness was classified according to a validated method based on the patients' ability to recognise symptoms during a hypoglycaemic episode (16). Subjects always recognising their symptoms were categorised as having normal awareness, those usually recognising their symptoms as having impaired awareness, and those occasionally or never recognising their symptoms as having unawareness. Data on patients' history of diabetes were extracted from medical records.

\section{Laboratory analyses}

At baseline, blood was sampled during daytime with subjects in the sitting position after resting in the clinic. Thereafter, blood was centrifuged and stored at $-80{ }^{\circ} \mathrm{C}$

Table 1 Clinical characteristics of 219 patients with type 1 diabetes. Data of two subgroups defined by the number of episodes of SH in the 1-year study period are also shown. Numbers are means (S.D.) or percentage, unless otherwise stated.

\begin{tabular}{|c|c|c|c|c|}
\hline & $\begin{array}{l}\text { All patients } \\
n=219\end{array}$ & $\begin{array}{l}\text { Patients with no } \\
\text { episodes of SH } \\
n=137\end{array}$ & $\begin{array}{l}\text { Patients with one or } \\
\text { more episodes of SH } \\
n=82\end{array}$ & $\boldsymbol{P}$ \\
\hline Age (years) & $46(13)$ & $44(13)$ & $49(12)$ & 0.009 \\
\hline Sex (\% female) & 41 & 39 & 43 & 0.63 \\
\hline Body mass index $\left(\mathrm{kg} / \mathrm{m}^{2}\right)$ & $25(3.6)$ & $26.5(3.8)$ & $24.1(3.2)$ & 0.008 \\
\hline Age of onset of diabetes (years) & $25(14)$ & $24(14)$ & $26(14)$ & 0.38 \\
\hline Duration of diabetes (years) & $21(12)$ & 20 (12) & $22(11)$ & 0.08 \\
\hline Detectable C-peptide $^{\text {a }}(\%)$ & 57.5 & 59.9 & 53.7 & 0.37 \\
\hline $\mathrm{HbA1c}(\%)$ & $8.5(1.1)$ & $8.6(1.2)$ & $8.2(1.0)$ & 0.01 \\
\hline $\begin{array}{l}\text { Retinopathy } \\
\text { None, simplex, proliferative (\%) }\end{array}$ & $46 / 39 / 15$ & $45 / 41 / 14$ & $49 / 36 / 15$ & 0.82 \\
\hline $\begin{array}{l}\text { Nephropathy } \\
\text { None/microalbuminuria/albuminuria/ } \\
\text { elevated serum creatinine (\%) }\end{array}$ & $78 / 15 / 6 / 1$ & $76 / 15 / 7 / 2$ & $81 / 14 / 4 / 1$ & 0.76 \\
\hline Peripheral neuropathy (\%) & 33 & 31 & 35 & 0.54 \\
\hline Autonomic neuropathy ${ }^{d}(\%)$ & 14 & 14 & 14 & 0.97 \\
\hline Myocardial infarction (\%) & 5.5 & 4.4 & 7.3 & 0.37 \\
\hline Stroke (\%) & 1.8 & 1.5 & 2.4 & 0.63 \\
\hline Amputation (\%) & 0.9 & 1.5 & 0 & 0.53 \\
\hline Hypertension (\%) & 17 & 18 & 16 & 0.73 \\
\hline Daily insulin dose/kg (units/kg) & $0.66(0.19)$ & $0.67(0.19)$ & $0.64(0.18)$ & 0.27 \\
\hline $\begin{array}{l}\text { Awareness of hypoglycaemia } \\
\text { Normal/impaired/unaware (\%) }\end{array}$ & $41 / 46 / 13$ & $53 / 38 / 9$ & $20 / 60 / 20$ & $<0.00001$ \\
\hline $\begin{array}{l}\text { Plasma EPO (U/I) } \\
\text { Median (range) }\end{array}$ & $\begin{array}{l}8.6 \\
(3.1-34.3)\end{array}$ & $\begin{array}{l}8.5 \\
(3.1-34.3)\end{array}$ & $\begin{array}{l}8.6 \\
(3.3-25.6)\end{array}$ & 0.45 \\
\hline $\begin{array}{l}\text { Serum VEGF (pg/ml) } \\
\text { Median (range) }\end{array}$ & $\begin{array}{l}52.2 \\
(6.6-337)\end{array}$ & $\begin{array}{l}52.4 \\
(6.6-337)\end{array}$ & $\begin{array}{l}49.9 \\
(6.8-242)\end{array}$ & 0.45 \\
\hline
\end{tabular}

$\mathrm{SH}$, severe hypoglycaemia; EPO, erythropoietin; VEGF, vascular endothelial growth factor. $P$ values refer to comparison between the two groups.

aDetection limit $=10 \mathrm{pmol} / \mathrm{l}$.

${ }^{\mathrm{b}} n=213$.

${ }^{\mathrm{c}} n=207$.

${ }^{d} n=137$. 
until analysis. Plasma EPO concentrations were measured using ELISA technique (R\&D Systems' Colorimetric Sandwich ELISA kit: Quantikine IVD, R\&D Systems, Europe, UK); detection limit is $\sim 0.1 \mathrm{U} / \mathrm{l}$; normal range is 6-18 U/l. Serum VEGF (VEGF-165) was measured using Elisa (Quantikine, R\&D Systems Inc., Minneapolis, MN, USA). The intra- and inter-assay coefficients of variation in VEGF, as indicated by the manufacturer, are 4.5 and $7.3 \%$ respectively. C-peptide was measured by RIA (Autodelfia, Wallac Oy, Turku, Finland). Subjects were classified as being C-peptide negative if the value was below the detection limit of $10 \mathrm{pmol} / \mathrm{l}$. Serum concentration of ACE was measured by a kinetics-based assay (Sigma Diagnostics). HbAlc was measured spectrophotometrically (DCA-2000, Bayer; normal range 4.1-6.4\%).

\section{Reporting and classification of hypoglycaemia}

Episodes of hypoglycaemia were reported monthly on questionnaires mailed to the participants. Events of severe hypoglycaemia defined as episodes with symptoms of hypoglycaemia with need for assistance from another person were reported by telephone within $24 \mathrm{~h}$ after the event. These episodes were the primary end point. Structured telephone interviews were carried out by two trained study nurses to establish the level of documentation, classify severity and explore circumstances of the incidents. Additionally, at the end of the follow-up period, severe hypoglycaemia was reported retrospectively by questionnaire, and in the case of missed reporting, telephone interviews were carried out. Episodes of severe hypoglycaemia were validated as previously described in detail (13). Mild hypoglycaemia was defined as episodes with symptoms familiar to the patient as hypoglycaemia, and managed solely by the patient. These episodes were reported for the week preceding the return of the monthly questionnaires.

\section{Statistical analysis}

Calculations were performed with SPSS software package (Version 17.0; Chicago, IL, USA). Since the distribution of episodes of severe hypoglycaemia (primary end point) is very skewed (17), a log-linear negative binomial model was applied (SPSS: Analyse $>$ Generalised Linear Models $>$ Negative binomial $>$ ). Events of severe hypoglycaemia were dependent variable. First, univariate analyses with serum VEGF or plasma EPO as explanatory variables were done. Secondly, a multivariate analysis with adjustment for C-peptide status, hypoglycaemia awareness status, duration of diabetes, baseline HbAlc, serum ACE, body mass index (BMI) and age was performed. BMI and age were included in the model since these factors may influence the concentration of circulating $\operatorname{VEGF}(18,19)$. Regression coefficients were transformed into percentage by means of the natural logarithm $\left(e^{\text {coefficient }}\right)$.
Any associations between mild hypoglycaemia and levels of EPO and VEGF were calculated using univariate and multivariate linear regression (before analysis, mean episodes of mild hypoglycaemia were logarithmically transformed $\left(\log _{10}\right)$, and regression coefficients were back-transformed to percentage). In the multivariate analysis adjustment for C-peptide status, hypoglycaemia awareness status, duration of diabetes, baseline HbAlc, serum ACE, BMI and age were performed. Associations between the levels of EPO and VEGF and demographic and diabetes-related variables were calculated using univariate and multivariate linear regression (the levels of EPO and VEGF were logarithmically transformed $\left(\log _{10}\right)$, and regression coefficients were back-transformed to percentage). Comparisons between the subgroups in Table 1 were done by independent $t$-tests for continuous variables (logarithmised values were used in case of non-normally distributed values) or Pearson's $\chi^{2}$-test for categorical variables (or Fisher's exact test, when relevant). A two-tailed $P$ value of $<0.05$ was considered statistically significant.

\section{Results}

\section{Reported episodes of hypoglycaemia}

A total of 82 of the 219 patients (37\%) contributed to 235 episodes of severe hypoglycaemia during the 1-year study period, corresponding to 1.1 episodes per patientyear. Patients who experienced one or more episodes of severe hypoglycaemia and reported a mean of 2.9 episodes per patient-year were older with a longer duration of diabetes, lower HbAlc and BMI, and more frequently had impaired hypoglycaemia awareness (Table 1). The frequency of mild hypoglycaemia was 1.7 episodes per patient-week.

\section{Plasma EPO and serum VEGF concentrations}

The plasma concentration of EPO was 8.6 (3.1-34.3) U/l (median (range)), and the serum concentration of VEGF was 52.2 (6.6-337) pg/ml. Eighteen patients had a blood glucose value below $3.1 \mathrm{mmol} / \mathrm{l}$ (mean 2.24 (s.D. 0.7$) \mathrm{mmol} / \mathrm{l}$ ), but no symptoms of hypoglycaemia were observed when blood samples were taken. The EPO and VEGF values in these patients did not differ from those with blood glucose values higher than $3.1 \mathrm{mmol} / \mathrm{l}$ $(P=0.47$ and $P=0.63$ respectively). There was no association between the levels of EPO and VEGF (data not shown).

\section{Association between EPO and VEGF and episodes of severe hypoglycaemia}

There was neither association between concentrations of plasma EPO nor serum VEGF and the number of episodes of severe hypoglycaemia in the study period 
(Table 2 and Fig. 1a and b). Adjustment for duration of diabetes, HbAlc, serum ACE, hypoglycaemia awareness status (normal awareness, impaired awareness and unawareness), C-peptide status (detectable and undetectable), BMI and age did not change the results. Analyses excluding the 18 subjects with hypoglycaemia during blood sampling did not change the results. Neither did removal of 123 subjects with late diabetic complications, i.e. albuminuria, retinopathy or previous stroke/myocardial infarction, change the results. Finally, removing subjects treated with $\beta$-receptor antagonists $(n=5)$ or psychopharmacologic agents $(n=3)$ from the analysis did not change the results.

\section{Association between EPO and VEGF and episodes of mild hypoglycaemia}

The frequency of mild hypoglycaemia was not associated with the levels of EPO and VEGF either in univariate or multivariate analyses with adjustment for duration of diabetes, HbAlc, serum ACE, awareness status, C-peptide status, age and BMI (Table 2).

\section{Demographic and diabetes-related characteristics and concentrations of EPO and VEGF}

No demographic and diabetes-related characteristics (age, sex, diabetes duration, BMI, HbAlc at baseline, C-peptide or hypoglycaemia awareness category) were significantly associated with the levels of plasma EPO in a multivariate analysis (Table 3). Age was positively associated with serum VEGF levels $(P=0.03)$ with an increase in VEGF of $1.2 \%$ (95\% confidence interval (CI): $0.2-2.3 \%$ ) for every 1 -year increase in age (Table 3 ) in a multivariate analysis. Female sex was associated with a 26\% (95\% CI: $1.4-44 \%$ ) higher concentration of VEGF $(P=0.04)$. No other variables were associated with the level of VEGF.

\section{Discussion}

As opposed to our hypothesis, we found in this study that the concentrations of circulating EPO and VEGF are not associated with the number of prospectively recorded episodes of severe hypoglycaemia. Nor did we find an association between circulating EPO and VEGF and the frequency of mild hypoglycaemia. This is surprising, since both EPO and VEGF are probably involved in glucose metabolism and may also affect brain metabolism. Excluding subjects with hypoglycaemia during blood sampling, subjects with late diabetic complications which may alter EPO or VEGF levels and subjects treated with $\beta$-receptor antagonists or psychopharmacological agents did not change the results.

In recent years, a neuroprotective role has emerged for EPO in conditions with impaired substrate supply (20). EPO and its receptor are produced in the brain, especially in response to intracerebral metabolic stress such as acute brain hypoxia $(21,22)$. EPO receptors are also located in rat and mouse brain endothelial cells (23). A number of in vitro studies suggest that EPO may preserve cellular function during hypoglycaemia (8-10). A study by Miskowiak et al. $(24,25)$ has demonstrated that high-dose EPO treatment modulates neural processing in healthy adults and may improve cognitive function. We recently demonstrated in patients with type 1 diabetes that the concentration of EPO increases during hypoglycaemia, and that low baseline EPO levels may be associated with more pronounced cerebral dysfunction during hypoglycaemia (nadir plasma glucose concentration $2.2 \mathrm{mmol} / \mathrm{l}$ ) than higher levels of EPO (1). VEGF, a potent regulator of normal and pathological angiogenesis (26), enhances glucose transport across the blood-retina barrier, most likely via translocation of the insulin-independent GLUT1 to the plasma membrane (27). GLUT1 mRNA is also up-regulated by VEGF in an endothelial cellular model (12). Under normal conditions, GLUT1-mediated

Table 2 Regression coefficients (95\% Cls) for concentrations of serum VEGF and plasma EPO (explanatory variables) in a generalised linear model (negative binomial distribution) with episodes of severe hypoglycaemia as dependent variable. The coefficients have been transformed into percentage by means of the natural logarithm $\left(e^{\text {coefficient }}\right)$. In the analysis of mild hypoglycaemia, a regression analysis has been done. The regression coefficients $(95 \% \mathrm{Cls}$ ) have been back-transformed to percentage since the episodes of mild hypoglycaemia were logarithmically transformed $\left(\log _{10}\right)$. Two-hundred and nineteen patients with type 1 diabetes are included in the analysis. The multivariate analyses are adjusted for $\mathrm{HbAlc}$, duration of diabetes, serum angiotensin-converting enzyme (ACE), hypoglycaemia awareness status, C-peptide status, body mass index and age.

\begin{tabular}{lcccc}
\hline & \multicolumn{4}{c}{ Regression coefficients } \\
\cline { 2 - 5 } Variable & Univariate & $P$ & Multivariate & $P$ \\
\hline & Severe hypoglycaemia (episodes/year), percentage change per unit change in explanatory variable \\
EPO $(\mathrm{U} / \mathrm{l})$ & $0.6(-3.9 \rightarrow 5.1)$ & 0.79 & $-0.7(-5.6 \rightarrow 4.5)$ & 0.79 \\
VEGF $(\mathrm{pg} / \mathrm{ml})$ & $-0.1(-0.4 \rightarrow 0.2)$ & 0.50 & $0(-0.4 \rightarrow 0.3)$ & 0.75 \\
& Mild hypoglycaemia (episodes/week) & percentage change per unit change in explanatory variable \\
EPO $(\mathrm{U} / \mathrm{l})$ & $1.6(-0.69 \rightarrow 4.2)$ & 0.18 & $1.4(-1.1 \rightarrow 3.8)$ & 0.28 \\
VEGF $(\mathrm{pg} / \mathrm{ml})$ & $0(-0.3 \rightarrow 0.2)$ & 0.58 & $0(-0.2 \rightarrow 0.2)$ & 0.64 \\
\hline
\end{tabular}

EPO, erythropoietin; VEGF, vascular endothelial growth factor. 

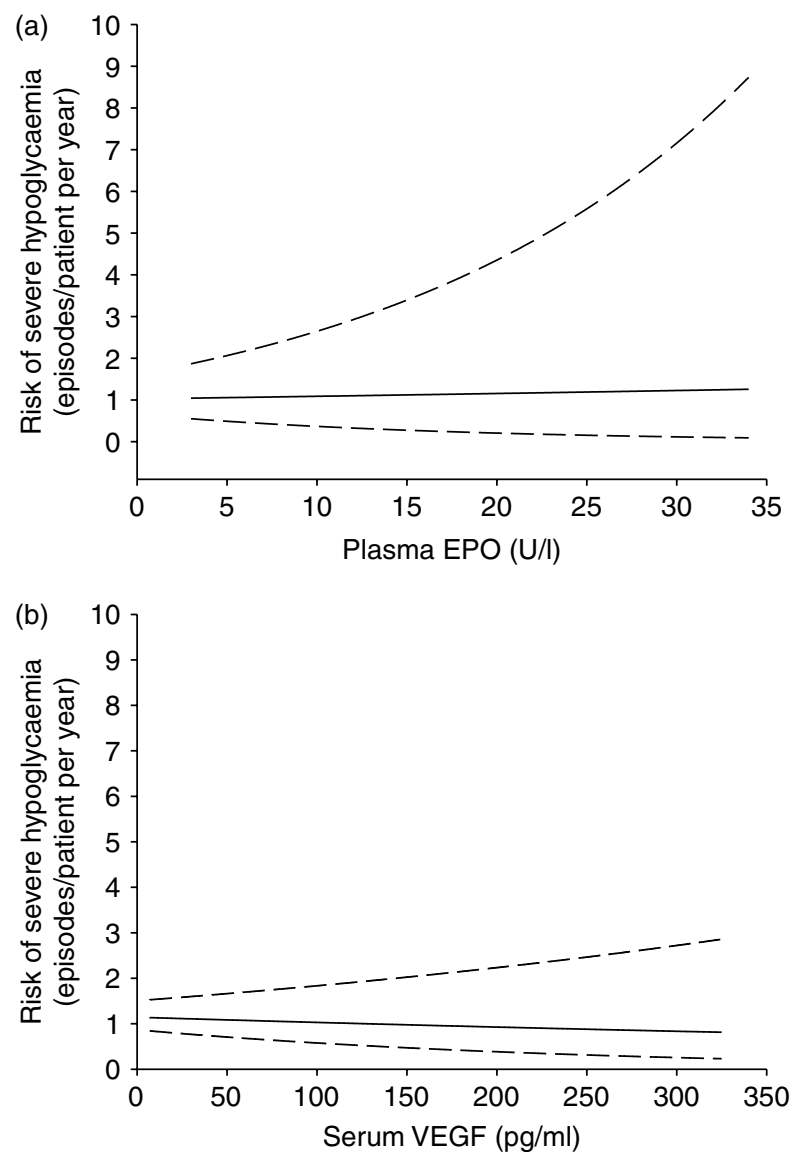

Figure 1 Relationship between concentration of plasma EPO (a) or serum VEGF (b) and rate of severe hypoglycaemia in 219 subjects with type 1 diabetes. Since the distribution of episodes of severe hypoglycaemia (dependent variable) is very skewed, a log-linear negative binomial model was applied. Dashed lines show 95\% confidence limits.

glucose transport is not rate limiting for glucose metabolism in the brain. However, when blood glucose levels are reduced to $2-3 \mathrm{mmol} / \mathrm{l}$, the transport of glucose through GLUT1 becomes rate limiting to glycolysis in neurons (28). VEGF concentrations have been shown to increase during hypoglycaemia in cells (human monocytic cell line) (29), in healthy adults (3-5) and in people with type 1 diabetes (2). Accordingly, in cell models, hypoglycaemia induces stabilisation of VEGF mRNA (11). Moreover, a high VEGF rise during hypoglycaemia in one study was associated with preservation of cognitive function during hypoglycaemia in healthy adults (4). In contrast, brief hyperglycaemia seems to down-regulate VEGF (3). Because hypothalamic cells involved in neuroendocrine regulation with afferent projections to blood glucoseresponsive cells can synthesise VEGF, VEGF may play a central role in regulating glucose transport across the blood-brain barrier (30). Hence, if EPO and VEGF play important roles in transport of glucose from bloodstream to neurons and intracerebral glucose metabolism, our results indicate that this role is primarily exerted in a paracrine or autocrine manner.

We found no differences in VEGF and EPO when comparing the 18 subjects who were hypoglycaemic during blood collection (but without symptoms of hypoglycaemia) at baseline and those subjects who were either eu- or hyperglycaemic. This was rather unexpected since VEGF (repeatedly) and EPO (once) have been found to increase during experimental hypoglycaemia (1-5). The unchanged VEGF and EPO level may be a consequence of (long-standing) diabetes as indicated by a comparison of the magnitude of the VEGF response during hypoglycaemia in people without and with diabetes $(2,4)$. We do not know for how long the subjects with asymptomatic hypoglycaemia had been exposed to hypoglycaemia when the non-arterialised venous blood was collected. Short-term hypoglycaemia probably has lesser stimulating impact on VEGF levels than a more robust hypoglycaemic stimulus. Furthermore, antecedent hypoglycaemia leads to a clearly diminished VEGF response, which has been demonstrated by Merl et al. (5). Since many of the patients with plasma glucose below $3.1 \mathrm{mmol} / \mathrm{l}$ suffer from impaired hypoglycaemia awareness, it is plausible that they have been exposed to antecedent low plasma glucose values recently. It is also possible that collection of blood samples and recruitment of subjects to hypoglycaemic clamp experiments were standardised to a further extent than in the present study, leading to lower variation in VEGF and EPO during experimental hypoglycaemia.

No significant associations were found between circulating EPO and any demographic or diabetesrelated characteristics. This is in contrast to studies reporting that plasma EPO is either positively (31) or negatively associated with age (32), negatively associated with duration of diabetes (31) and negatively correlated with HbAlc (33). Unfortunately, information about EPO levels in unselected patients with type 1 diabetes is very limited, and most studies have focused on anaemia or diabetic neuropathy and nephropathy. New cross-sectional and longitudinal studies elucidating possible roles of endogenous EPO in other aspects of diabetes are therefore warranted. The positive association between age and serum VEGF levels in our study is in accordance with a study by Chiarelli et al. (34) and partly with a study by Sandhofer et al. (18), but in contrast to a study by Chaturvedi et al. (35). In accordance with our results, Chaturvedi et al. (35) did not find any associations between VEGF level and duration of diabetes or HbAlc. This is, however, opposed by a study by Lim et al. (36) who found a positive association between VEGF and HbAlc in people with type 1 diabetes. The reduction in VEGF associated with male sex is in accordance with a study by MalamitsiPuchner et al. (37). It should, however, be kept in mind that age and gender only account for a small proportion of variance in VEGF in the present study. Lack of 
Table 3 Multiple regression analyses of associations between logarithmic values $\left(\log _{10}\right)$ of plasma EPO and serum VEGF and demographic and diabetes-related characteristics in 219 patients with type 1 diabetes. The logarithmic regression coefficients and Cls have been back-transformed to percentage.

\begin{tabular}{|c|c|c|c|c|c|c|c|c|}
\hline \multirow[b]{3}{*}{ Age (years) } & \multicolumn{8}{|c|}{ Percentage change in EPO/VEGF per one unit of explanatory variable } \\
\hline & \multirow{2}{*}{$\frac{\text { EPO }}{0}$} & \multicolumn{2}{|c|}{$\mathrm{Cl} 95 \%$} & \multirow{2}{*}{$\frac{P}{0.73}$} & \multirow{2}{*}{$\frac{\text { VEGF }}{1.2}$} & \multicolumn{2}{|c|}{ Cl $95 \%$} & \multirow{2}{*}{$\frac{P}{0.03}$} \\
\hline & & -0.7 & 0.5 & & & 0.2 & 2.3 & \\
\hline Sex (female versus male) & -9.4 & -20.6 & 3.5 & 0.14 & -25.8 & -44.3 & -1.4 & 0.04 \\
\hline Duration of diabetes (years) & 0 & -0.7 & 0.5 & 0.90 & 1.2 & 0 & 2.3 & 0.10 \\
\hline Body mass index $\left(\mathrm{kg} / \mathrm{m}^{2}\right)$ & 0 & -2.1 & 1.6 & 0.84 & 1.4 & -2.7 & 5.4 & 0.53 \\
\hline $\mathrm{HbA} 1 \mathrm{c}$ at baseline $(\%)$ & 1.2 & -4.3 & 6.7 & 0.69 & 5.2 & -6.5 & 18.3 & 0.40 \\
\hline C-peptide (pmol/l) & 0 & 0 & 0 & 0.72 & 0 & 0 & 0.2 & 0.69 \\
\hline $\begin{array}{l}\text { Categorised hypoglycaemia awareness } \\
\text { (aware } \rightarrow \text { impaired } \rightarrow \text { unaware) }\end{array}$ & -1.1 & -10.3 & 8.6 & 0.80 & -13.7 & -29.7 & 5.9 & 0.16 \\
\hline$R^{2}$ & 0.02 & & & & 0.04 & & & \\
\hline
\end{tabular}

$R^{2}$ is the proportion of variance in EPO and VEGF explained by the model. EPO, erythropoietin; VEGF, vascular endothelial growth factor; CI, confidence interval.

consensus between different studies probably reflects a combination of different methodology and different populations in the studies. However, to improve quality of future cross-sectional studies of circulating VEGF in patients with type 1 diabetes, credible data are warranted to identify clinical factors affecting VEGF levels.

The strength of our study is its prospective design with thorough gathering of data regarding the primary end point, i.e. episodes of severe hypoglycaemia. Moreover, we have used a statistical model that deals with the very skewed distribution of episodes of severe hypoglycaemia. Therefore, we have found that the results regarding the primary end point are reliable. Our study has limitations that may influence the results. First, severe hypoglycaemia may be underreported, at least in subjects with recurrent events (16). Especially, nocturnal episodes may not be registered, since these episodes may occur without notice of the patients or relatives. Secondly, the levels of VEGF and EPO may be influenced by several factors potentially biasing the study: the level of VEGF may change during the menstrual cycle (38), antecedent hypoglycaemia attenuates VEGF response to subsequent hypoglycaemia (5), and VEGF levels seem to affect carbohydrate intake (39). EPO measurements may show diurnal variations, although consensus on this topic has not been established $(40,41)$. This may be of importance since blood sampling was performed within a rather broad time period of about $6 \mathrm{~h}$. More standardised blood collection may lead to lower variation in EPO and VEGF, and unmask a statistically significant relationship between EPO/VEGF and the frequency of severe hypoglycaemia. However, the clinical goal of the present study is to determine the risk of future severe hypoglycaemic episodes by random measuring of VEGF and EPO, as it would be done in a clinical and practical context. In that situation, a relatively straightforward blood sample procedure is needed. Thirdly, it is a wellknown clinical observation that severe hypoglycaemia occurs due to poor self-care and may be affected by other confounders, such as severe liver problems or hormonal diseases. Owing to lack of robust measures of such confounders, we have had to include only broadly accepted risk factor in the analysis. Finally, the hypothesis that low VEGF levels are associated with increased risk of severe hypoglycaemia is based on clamped hypoglycaemic studies and cellular studies. The relationship - if any - between spontaneous circulating VEGF levels and stimulated hypoglycaemic levels of VEGF is unclear, and it is possible that a protective mechanism of brain function depends on raised hypoglycaemic VEGF levels and does not on spontaneously high euglycaemic concentrations of VEGF. This may explain the negative findings of the present study and challenges the hypothesis of the study.

The ability to predict severe hypoglycaemia would be a major advantage in daily diabetes management. To date, the only consistently reported biomarkers of severe hypoglycaemia in type 1 diabetes are undetectable C-peptide levels (42-44), low HbA1c (44-46) and high serum ACE activity $(13,43,47,48)$. However, these markers only explain a minor proportion of the risk variation between subjects. We conclude that random measurements of serum VEGF or plasma EPO levels do not add to prediction of risk of severe hypoglycaemia in type 1 diabetes. Further efforts should be directed towards the identification of new biomarkers for severe hypoglycaemia, enabling improved understanding, prediction and prevention of this major clinical problem in type 1 diabetes.

\section{Declaration of interest}

The authors declare that there is no conflict of interest that could be perceived as prejudicing the impartiality of the research reported.

\section{Funding}

This work was supported by The Foundation of O B Nielsen, The Research Foundation of Hillerød Hospital (former Frederiksborg County), The Foundation of $\mathrm{H}$ Jensen and wife, The Foundation of Region 3, The Danish Diabetes Association and The A P Møller Foundation for the Advancement of Medical Science. 


\section{Acknowledgements}

We thank research nurses P Banck and T Larsen for careful handling of patients and data, and statistician P Hougaard and M D Lise Tarnow for guidance. Research technicians M Pedersen, K Velin and M Wolf, and G Sölétormos, MD, DMSc, the Research Unit at the Clinical Biochemical Department, Hillerød Hospital, are thanked for cooperation. The staff at the outpatient diabetes clinic, Endocrinology Section, Hillerød Hospital, is acknowledged for their cooperation during the patient recruitment phase.

\section{References}

1 Kristensen PL, Hoi-Hansen T, Olsen NV, Pedersen-Bjergaard U \& Thorsteinsson B. Erythropoietin during hypoglycaemia in type 1 diabetes: relation to basal renin-angiotensin system activity and cognitive function. Diabetes Research and Clinical Practice 200985 75-84.

2 Kristensen PL, Hoi-Hansen T, Boomsma F, Pedersen-Bjergaard U \& Thorsteinsson B. Vascular endothelial growth factor during hypoglycemia in patients with type 1 diabetes mellitus: relation to cognitive function and renin-angiotensin system activity. Metabolism 200958 1430-1438.

3 Oltmanns KM, Melchert UH, Scholand-Engler HG, Schultes B, Schweiger U \& Peters A. Divergent effects of hyper- and hypoglycemia on circulating vascular endothelial growth factor in humans. Metabolism 200857 90-94.

4 Dantz D, Bewersdorf J, Fruehwald-Schultes B, Kern W, Jelkmann W, Born J, Fehm HL \& Peters A. Vascular endothelial growth factor: a novel endocrine defensive response to hypoglycemia. Journal of Clinical Endocrinology and Metabolism $2002 \mathbf{8 7}$ 835-840.

5 Merl V, Peters A, Oltmanns KM, Kern W, Hubold C, Fehm HL, Born J \& Schultes B. Antecedent hypoglycaemia attenuates vascular endothelial growth factor response to subsequent hypoglycaemia in healthy men. Diabetic Medicine 200522 1278-1281.

6 Heidbreder M, Qadri F, Johren O, Dendorfer A, Depping R, Frohlich F, Wagner KF \& Dominiak P. Non-hypoxic induction of HIF-3alpha by 2-deoxy-D-glucose and insulin. Biochemical and Biophysical Research Communications 2007352 437-443.

7 Wenger RH. Cellular adaptation to hypoxia: $\mathrm{O}_{2}$-sensing protein hydroxylases, hypoxia-inducible transcription factors, and $\mathrm{O}_{2}$-regulated gene expression. FASEB Journal $2002 \mathbf{1 6}$ 1151-1162.

8 Ghosal J, Chakraborty M, Biswas T, Ganguly CK \& Datta AG. Effect of erythropoietin on the glucose transport of rat erythrocytes and bone marrow cells. Biochemical Medicine and Metabolic Biology 198738 134-141.

9 Yamamoto M, Koshimura K, Kawaguchi M, Sohmiya M, Murakami Y \& Kato Y. Stimulating effect of erythropoietin on the release of dopamine and acetylcholine from the rat brain slice. Neuroscience Letters 2000292 131-133.

10 Weber A, Maier RF, Hoffmann U, Grips M, Hoppenz M, Aktas AG, Heinemann U, Obladen M \& Schuchmann S. Erythropoietin improves synaptic transmission during and following ischemia in rat hippocampal slice cultures. Brain Research 2002958 305-311.

11 Park SH, Kim KW, Lee YS, Baek JH, Kim MS, Lee YM, Lee MS \& Kim YJ. Hypoglycemia-induced VEGF expression is mediated by intracellular $\mathrm{Ca}^{2+}$ and protein kinase $\mathrm{C}$ signaling pathway in HepG2 human hepatoblastoma cells. International Journal of Molecular Medicine 20017 91-96.

12 Pekala P, Marlow M, Heuvelman D \& Connolly D. Regulation of hexose transport in aortic endothelial cells by vascular permeability factor and tumor necrosis factor-alpha, but not by insulin. Journal of Biological Chemistry $1990 \mathbf{2 6 5} 18051-18054$.
13 Pedersen-Bjergaard U, Agerholm-Larsen B, Pramming S, Hougaard P \& Thorsteinsson B. Prediction of severe hypoglycaemia by angiotensin-converting enzyme activity and genotype in type 1 diabetes. Diabetologia $2003 \mathbf{4 6} 89-96$.

14 Wolf G, Schroeder R \& Stahl RA. Angiotensin II induces hypoxiainducible factor-1 alpha in PC 12 cells through a posttranscriptional mechanism: role of AT2 receptors. American Journal of Nephrology 200424 415-421.

15 Pedersen-Bjergaard U, Dhamrait SS, Sethi AA, Frandsen E, Nordestgaard BG, Montgomery HE, Pramming S, Hougaard P \& Thorsteinsson B. Genetic variation and activity of the reninangiotensin system and severe hypoglycemia in type 1 diabetes. American Journal of Medicine 2008121 246.E1-246.E8.

16 Pedersen-Bjergaard U, Pramming S \& Thorsteinsson B. Recall of severe hypoglycaemia and self-estimated state of awareness in type 1 diabetes. Diabetes/Metabolism Research and Reviews 200319 232-240.

17 Pedersen-Bjergaard U, Pramming S, Heller SR, Wallace TM, Rasmussen AK, Jorgensen HV, Matthews DR, Hougaard P \& Thorsteinsson B. Severe hypoglycaemia in 1076 adult patients with type 1 diabetes: influence of risk markers and selection. Diabetes/Metabolism Research and Reviews $200420479-486$.

18 Sandhofer A, Tatarczyk T, Kirchmair R, Iglseder B, Paulweber B, Patsch JR \& Schratzberger P. Are plasma VEGF and its soluble receptor sFlt-1 atherogenic risk factors? Cross-sectional data from the SAPHIR study Atherosclerosis 2009206 265-269.

19 Wada H, Satoh N, Kitaoka S, Ono K, Morimoto T, Kawamura T, Nakano T, Fujita M, Kita T, Shimatsu A \& Hasegawa K. Soluble VEGF receptor-2 is increased in sera of subjects with metabolic syndrome in association with insulin resistance. Atherosclerosis 2010208 512-517.

20 Hasselblatt M, Ehrenreich H \& Siren AL. The brain erythropoietin system and its potential for therapeutic exploitation in brain disease. Journal of Neurosurgical Anesthesiology 200618 132-138.

21 Siren AL, Knerlich F, Poser W, Gleiter CH, Bruck W \& Ehrenreich H. Erythropoietin and erythropoietin receptor in human ischemic/hypoxic brain. Acta Neuropathologica $2001 \mathbf{1 0 1}$ 271-276.

22 Springborg JB, Sonne B, Frederiksen HJ, Foldager N, Poulsgaard L, Klausen T, Jorgensen OS \& Olsen NV. Erythropoietin in the cerebrospinal fluid of patients with aneurysmal subarachnoid haemorrhage originates from the brain. Brain Research $2003 \mathbf{9 8 4}$ 143-148.

23 Yamaji R, Okada T, Moriya M, Naito M, Tsuruo T, Miyatake K \& Nakano Y. Brain capillary endothelial cells express two forms of erythropoietin receptor mRNA. European Journal of Biochemistry $1996239494-500$.

24 Miskowiak K, Inkster B, O’Sullivan U, Selvaraj S, Goodwin GM \& Harmer CJ. Differential effects of erythropoietin on neural and cognitive measures of executive function 3 and 7 days postadministration. Experimental Brain Research 2008184 313-321.

25 Miskowiak K, Inkster B, Selvaraj S, Wise R, Goodwin GM \& Harmer CJ. Erythropoietin improves mood and modulates the cognitive and neural processing of emotion 3 days post administration. Neuropsychopharmacology 200833 611-618.

26 Ferrara N \& Davis-Smyth T. The biology of vascular endothelial growth factor. Endocrine Reviews 199718 4-25.

27 Sone H, Deo BK \& Kumagai AK. Enhancement of glucose transport by vascular endothelial growth factor in retinal endothelial cells. Investigative Ophthalmology \& Visual Science 200041 1876-1884.

28 Gruetter R, Novotny EJ, Boulware SD, Rothman DL, Mason GF, Shulman GI, Shulman RG \& Tamborlane WV. Direct measurement of brain glucose concentrations in humans by $13 \mathrm{C}$ NMR spectroscopy. PNAS 199289 1109-1112.

29 Satake S, Kuzuya M, Miura H, Asai T, Ramos MA, Muraguchi M, Ohmoto Y \& Iguchi A. Up-regulation of vascular endothelial growth factor in response to glucose deprivation. Biology of the Cell $199890161-168$.

30 Peters A, Schweiger U, Fruhwald-Schultes B, Born J \& Fehm HL. The neuroendocrine control of glucose allocation. Experimental and Clinical Endocrinology E Diabetes $2002110199-211$. 
31 Kim MK, Baek KH, Lim DJ, Kim YK, Kang MI, Lee KW \& Song KH. Erythropoietin response to anemia and its association with autonomic neuropathy in type 2 diabetic patients without advanced renal failure. Journal of Diabetes and its Complications 200924 90-95.

32 Mojiminiyi OA, Abdella NA, Zaki MY, El Gebely SA, Mohamedi HM \& Aldhahi WA. Prevalence and associations of low plasma erythropoietin in patients with type 2 diabetes mellitus. Diabetic Medicine 200623 839-844.

33 Symeonidis A, Kouraklis-Symeonidis A, Psiroyiannis A, Leotsinidis M, Kyriazopoulou V, Vassilakos P, Vagenakis A \& Zoumbos N. Inappropriately low erythropoietin response for the degree of anemia in patients with noninsulin-dependent diabetes mellitus. Annals of Hematology 200685 79-85.

34 Chiarelli F, Spagnoli A, Basciani F, Tumini S, Mezzetti A, Cipollone F, Cuccurullo F, Morgese G \& Verrotti A. Vascular endothelial growth factor (VEGF) in children, adolescents and young adults with type 1 diabetes mellitus: relation to glycaemic control and microvascular complications. Diabetic Medicine 2000 17 650-656.

35 Chaturvedi N, Fuller JH, Pokras F, Rottiers R, Papazoglou N \& Aiello LP. Circulating plasma vascular endothelial growth factor and microvascular complications of type 1 diabetes mellitus: the influence of ACE inhibition. Diabetic Medicine 2001 18 288-294.

36 Lim HS, Blann AD, Chong AY, Freestone B \& Lip GY. Plasma vascular endothelial growth factor, angiopoietin-1, and angiopoietin-2 in diabetes: implications for cardiovascular risk and effects of multifactorial intervention. Diabetes Care 200427 2918-2924.

37 Malamitsi-Puchner A, Tziotis J, Tsonou A, Protonotariou E, Sarandakou A \& Creatsas G. Changes in serum levels of vascular endothelial growth factor in males and females throughout life. Journal of the Society for Gynecologic Investigation 20007 309-312.

38 Caccamo C, Nostro L, Giorgianni G, Mondello S, Crasci E, Frisina N \& Buemi M. Behavior of vascular endothelial growth factor and erythropoietin throughout the menstrual cycle in healthy women. Journal of Reproductive Medicine 200752 1035-1039.
39 Hubold C, Oltmanns KM, Schultes B, Jelkmann W, Born J, Fehm HL, Schweiger U \& Peters A. High plasma VEGF relates to low carbohydrate intake in patients with type 2 diabetes. International Journal of Obesity 200630 1356-1361.

40 Klausen T, Dela F, Hippe E \& Galbo H. Diurnal variations of serum erythropoietin in trained and untrained subjects. European Journal of Applied Physiology and Occupational Physiology 199367 $545-548$.

41 Roberts D \& Smith DJ. Erythropoietin does not demonstrate circadian rhythm in healthy men. Journal of Applied Physiology $199680847-851$.

42 Muhlhauser I, Overmann H, Bender R, Bott U \& Berger M. Risk factors of severe hypoglycaemia in adult patients with type I diabetes - a prospective population based study. Diabetologia 1998 41 1274-1282.

43 Pedersen-Bjergaard U, Agerholm-Larsen B, Pramming S, Hougaard P \& Thorsteinsson B. Activity of angiotensin-converting enzyme and risk of severe hypoglycaemia in type 1 diabetes mellitus. Lancet $20013571248-1253$.

44 The DCCT Research Group. Hypoglycemia in the Diabetes Control and Complications Trial. The Diabetes Control and Complications Trial Research Group. Diabetes 199746 271-286.

45 Allen C, LeCaire T, Palta M, Daniels K, Meredith M \& D’Alessio DJ. Risk factors for frequent and severe hypoglycemia in type 1 diabetes. Diabetes Care 200124 1878-1881.

46 Pramming S, Thorsteinsson B, Bendtson I \& Binder C. Symptomatic hypoglycaemia in 411 type 1 diabetic patients. Diabetic Medicine 19918 217-222.

47 Nordfeldt S \& Samuelsson U. Serum ACE predicts severe hypoglycemia in children and adolescents with type 1 diabetes. Diabetes Care 200326 274-278.

48 Zammitt NN, Geddes J, Warren RE, Marioni R, Ashby JP \& Frier BM. Serum angiotensin-converting enzyme and frequency of severe hypoglycaemia in type 1 diabetes: does a relationship exist? Diabetic Medicine 200724 1449-1454.

Received 8 June 2010

Accepted 21 June 2010 